\title{
INVESTIGATION OF THE EFFECT OF IFRS 16 ON BIST 100 COMPANIES' FINANCIAL INDICATORS
}

\author{
DOI: 10.17261/Pressacademia.2019.1073 \\ PAP- V.9-2019(20)-p.90-94
}

Emre Selcuk Sari ${ }^{1}$, Nevzat Gungor ${ }^{2}$

${ }^{1}$ Istanbul University, School of Business, Istanbul, Turkey. sari@istanbul.edu.tr, ORCID: 0000-0001-6675-3214

2 stanbul University, School of Business, Istanbul, Turkey. nevzat.gungor@istanbul.edu.tr, ORCID: 0000-0001-9883-1985

To cite this document

Sari, E. S., Gungor, N., (2019). Investigation of the effect of IFRS 16 on BIST 100 companies' financial indicators. PressAcademia Procedia (PAP), V.9, p.90-94

Permemant link to this document: http://doi.org/10.17261/Pressacademia.2019.1073

Copyright: Published by PressAcademia and limited licenced re-use rights only.

\section{ABSTRACT}

Purpose- Over the years, the Financial Accounting Standards Board (FASB) and International Accounting The Standards Board (IASB) has made numerous amendments to controversial lease accounting rules. In order to increase transparency and comparability, IFRS 16 Leases Standard published by the IASB will be implemented as of January 1, 2019. Operating leases will require capitalization in accordance with this standard. The purpose of this paper is to analyze the impact of the new leasing standard on the financial statements and ratios of the firms and industries represented in the BIST 100 indice under a variety of assumptions.

Methodology- The financial statements and disclosures of the 63 non-financial companies listed in BIST 100 are investigated. Under various assumptions; the effect of IFRS 16 on the financial statements are measured. In this context, it was assumed in 2017, companies used IFRS 16 instead of IAS 17. The related accounts are recalculated accordingly. Thus, it is possible to see the effect on the financial statements and financial statements items according to IAS 17 and IFRS 16.

Findings- As a result of the calculations and analysis, decrease in profit for the period; and increase in operating profit before financial income/expense, operating profit, financial expenses, total assets and total labilities are determined.

Conclusion- With the adoption of IFRS 16, the rights and liabilities related to the operating leases will be reported on the balance sheet. In this way, the comparability will increase and financial ratios will become more significant. This will also have an impact on strengthening the fair presentation of the financial statements.
\end{abstract}

Keywords: IFRS 16, IAS 17, operating lease, capital lease, financial performance.

JEL Codes: M40, M41, M48.

\section{UFRS 16'NIN BIST 100 ŞIRKETLERI'NIN FINANSAL GÖSTERGELERINE ETKISI ÜZERINE BIR INCELEME}

\section{ÖZET}

Amaç- Yıllar boyunca, Finansal Muhasebe Standartları Kurulu (FASB) ve Uluslararası Muhasebe Standartları Kurulu (IASB) üzerinde pekçok tartışma yaşanan finansal kiralama kurallarına ilişkin değişiklikler yapmışlardır. Şeffaflığı ve karşılaştırılabilirliği arttırmak için, IASB tarafından yayınlanan UFRS 16 Finansal Kiralama Standardı 1 Ocak 2019 tarihinden itibaren uygulanacaktır. Bu çalışmanın amacı, yeni finansal kiralama standardının BIST 100 endeksinde faaliyet gösteren firmaların finansal tabloları ve oranları üzerindeki etkisini çeşitli varsayımlar altında analiz etmektir.

Yöntem- BIST 100'de listelenen 63 finansal olmayan şirketin finansal tabloları ve açıklamaları incelenmiştir. Çeşitli varsayımlar altında; UFRS 16 'nın finansal tablolara etkisi ölçülmüştür. Bu çerçevede, 2017 yılında UMS 17 yerine UFRS 16 kullandıkları varsayılmıştır. İlgili hesaplar buna göre yeniden hesaplanmıştır. Böylece finansal tablolar ve finansal tablo kalemleri üzerindeki etkisini UMS 17 ve UFRS 16 'ya göre görmek mümkün olmuştur.

Bulgular- Hesaplamalar ve analizler sonucunda dönem karında azalış; finansman gideri öncesi faaliyet kârı esas faaliyet kârı, faiz gideri, toplam varlıklar ve toplam borçlarda artış tespit edilmiştir.

Sonuç- UFRS 16'nın yürürlüğe girmesiyle birlikte, işletme kiralamalarıyla ilgili hak ve borçlar bilançoda raporlanacaktır. Bu sayede kıyaslanabilirlik artacak ve finansal oranlar daha önemli hale gelecektir. Bunun finansal tabloların adil sunumunun güçlendirilmesi üzerinde de etkisi olacaktır.

Anahtar Kelimeler: UFRS 16, UMS 17, faaliyet kiralaması, finansal kiralama, finansal performans JEL Kodları: M40, M41, M48. 


\section{GíRiş}

Kiralama Türk Dil Kurumu sözlüğünde "Bir taşınır veya taşınmazın kullanım hakkının belli bir süre için ve belli bir kira karşılığında kiracıya verilmesi" olarak tanımlanmaktadır. Kiralama işlemleri, özellikle işletmeler için satın alınması zor olan yüksek meblağlı varlıkların kullanılabilmesi ve bu varlıkların yaratacağı ekonomik faydaların kiracı işletme tarafından elde edilebilmesini sağlayan bir alternatiftir. Bilanço dışı finansman yöntemleri arasında yer alan kiralama işlemleri ile kavramsal olarak bir varlığın kullanım hakkı kira ödemeleri karşılığında sahibi tarafından kullanıcıya devredilmektedir (Sipahi, 2004: 3). Ancak kiralama işlemleri sonucu kiracı açısından ortaya çıkan hak ve yükümlülüklerin bilanço dışı bırakılması işletmelerin varlıklarının ve kaynakları toplamlarının ne kadar gerçekçi olduğu sorusuna neden olmaktadır. Kiralama işlemlerinin muhasebeleştirilmesi ve raporlanması yıllardır akademik çevreler, standart koyucular, işletme yöneticileri ve finansal tablo kullanıcıları açısından tartışmalı bir konu olmuştur (Tai, 2013:129). Amerikan Sermaye Piyasası Kurulu (SEC) 2005 yılında Amerika Birleşik Devletleri $(A B D)$ 'ndeki halka açık şirketlerin bilanço dışı bıraktığı kiralama işlemlerinin toplam tutarının yaklaşık 1,25 trilyon ABD doları olduğunu açıklamıştır. Faaliyet kiralamalarının 2019 yıından önce kiracının bilançosunda raporlanamamasının bilançoda raporlanan varlıklar ve yükümlülükler üzerinde önemli etkisi olduğu bilinmektedir (Altıntaş \& Türel, 2017:131).

Bu tartışmaları mümkün olduğunca giderebilmek amacıyla Uluslararası Muhasebe Standartları Kurulu (UMSK-IASB) ve Finansal Muhasebe Standartları Kurulu (FMSK-FASB) 2006 kiralama işlemlerinin muhasebeleştirilmesi ve raporlanmasına ilişkin ortak bir proje başlatmışlardır. Önemli bir kısmı G4+1 grubu tarafından yürütülen projenin odak noktası bir yıldan uzun süreli ve iptal edilmez olan tüm kiralama işlemlerinin bilançoda raporlanmasıydı (Fülbier, Silva \& Pferdehirt, (2008): 122-123). 2009 yılında IASB ve FASB resmi olarak yayımladıkları bir doküman ile yapılan çalışmayı sunmuş ve yoruma açmışlardır ve 2010 yılında taslak metin yayımlanmıştır (DiSalvio \& Dorata, (2014): 16-17). Taslak metinde tüm kiralama işlemlerinin bilançoda raporlanması gerektiği belirtilmekteydi ancak bu zorunluluk daha sonra değiştirilmiştir (Wong \& Joshi, (2015): 29). Yayınlanan taslakta kiralama işlemlerinin raporlanmasında "kullanım hakkı" modelinin uygulanması gerektiği üzerinde durmaktaydı. "Kullanım hakkı" modeline göre kiracının varlığı kullanmaktan doğan haklarının ve yükümlülüklerinin kiracının bilançosunda raporlanması gerekmekteydi (Lee, Paik \& Yoon, (2014): 46). Kiralama işlemlerine ilişkin çalışmaların tamamlanması sonucunda Uluslararası Muhasebe Standardı (UMS - IAS) 17'nin yerini alan Uluslararası Finansal Raporlama Standardı (UFRS - IFRS) 162016 yılının Ocak ayında yayımlanmıştır. UFRS 16 - Kiralamalar Standardı 31.12.2018 ve sonrasında başlayan hesap dönemleri için uygulamaya girmiş durumdadır. Türkiye'de UFRS 16 standardı Türkiye Finansal Raporlama Standardı (TFRS) 16 olarak Kamu Gözetimi Muhasebe ve Denetim Standartları Kurumu (KGK) tarafından çevrilmiş ve 16.4.2018 tarihli ve 29826 sayılı Resmi Gazete'de yayımlanmıştır. TFRS 16: Kiralamalar Standardı da 31.12.2018 tarihinde başlayan hesap dönemlerinde uygulanmak üzere Türkiye'de yürürlüğe girmiştir.

Bu çalışmada ilk olarak kiralama standardındaki değişikliğin finansal tablolara etkileri açısından konuya ilişkin daha önce yayınlanmış çalışmalar incelenecek, daha sonra ise Borsa İstanbul (BIST)'da yer alan işletmelerinin TFRS 16 standardını uygulamaları halinde finansal tablolarına olası etkileri değerlendirilecektir.

\section{LITERATÜR INCELEMESI}

Faaliyet kiralamalarının bilançoda varlık ve yükümlülükler arasında raporlanması konusunda ilk çalışma 1991 yılında Imhoff, Lipe ve Wright tarafından yapılmıştır. Çalışmada faaliyet kiralamalarının bilanço dışı bırakılmaması halinde varlıklara, yükümlülüklere ve işletme net kârına etkisi ayrıntılı olarak incelenmiştir. Fülbier, Silva ve Pferdehirt (2008) Almanya'da halka açık 90 işletmenin 2003 ve 2004 yılı verilerini kullanarak faaliyet kiralamalarının bilançoya alınmasının temel finansal oranlara etkilerini incelemişler ve tekstil ile perakendecilik sektöründe önemli etki yaratacağını tespit etmişlerdir. Hong Kong'da faaliyet gösteren iki restoran zinciri üzerinde çalışma yapan Tai (2013) faaliyet kiralamalarının bilançoda raporlanmasının aktif kârlıığı ve borç-özsermaye oranı üzerinde önemli etkisi olacağını belirlemiştir. Lee, Paik ve Yoon (2014), 1990-2011 yılları arasında Amerika Birleşik Devletleri (ABD)'nde faaliyet gösteren işletmelerin verilerini kullanarak faaliyet kiralamalarını bilançoda raporlamanın borçluluk yapısı, likidite ve finansal borç karşılama oranlarındaki etkisini incelemişlerdir. Çalışmada işletmeler üzerinde etkinin aynı olmadığı ve farklılıklar gösterdiğini tespit etmişlerdir. Paik, Smith, Lee ve Yoon (2015) bir diğer çalışmada lojistik regresyon analizi ile bilanço dışı kiralamaların etkisini inceleyerek faaliyet kiralamalarını bilançoda raporlamanın işletmelerin borçluluk oranlarını olumsuz etkileyeceği sonucuna ulaşmışlardır. Ericson ve Skarphagen (2015) faaliyet kiralamalarını bilançoda raporlamanın İsveç'te halka açık işletimlerin finansal oranlarına etkisini incelemişlerdir. 55 büyük ölçekli işletmenin incelendiği çalışmada yeni kiralama standardının borç-özsermaye oranı, aktif kârlılı̆ı ve özsermaye kârııı̆̆ı oranlarında önemli etkisi olacağı belirlenmiştir. Benzer bir çalışma da Avustralya'da halka açık olan 170 işletmenin 2010 yılı verileri kullanılarak Wong ve Joshi (2015) tarafından yapılmıştır. Çalışmanın sonuçlarına göre yeni kiralama standardı borç-özsermaye, borç-varlık ve varlık kârlılı̆̆ oranlarında istatistiksel olarak anlamlı etki yaratırken özsermaye kârlılığı üzerindeki etkisi istatistiksel olarak anlamsızdır.

Türkiye'de yapılan çalışmalarda ise Sarı, Altıntaş ve Taş (2016) perakendecilik sektöründe BisT'te yer alan işletmelerin finansal verilerini incelemişler ve IFRS 16 standardının uygulanması halinde borç-varlık oranında istatistiki açıdan anlamlı bir fark olmayacağını ancak borçözkaynak oranında istatistiki açıdan anlamlı değişim yaşanacağını belirlemişlerdir. Acar, Temiz ve Aktaş (2017) çalışmalarında BisT'te ye alan perakende, taşımacılık, turizm ve telekomünikasyon sektörü işletmelerinin verilerini inceleyerek UFRS 16'nın uygulanması halinde kaldıraç oranlarının artacağı, kâr marjı, aktif kârlılığı ve özsermaye kârlıı̆ğı oranlarında anlamlı değişim olacağını tespit etmişlerdir. Serçemeli ve Öztürk (2016) çalışmalarında IFRS 16'nın yaratacağı değişiklikleri incelemişlerdir. Yazarlar çalışmaları sonucunda IFRS 16'ile varlık ve yükümlülüklerin daha gerçekçi bir sunuma sahip olacağı, karşılaştırılabilirliğin artacağı ve IFRS 16 etkisinin sektörlere göre farklılık göstereceği sonucuna ulaşmışlardır. Öztürk 2016 yılında gerçekleştirdiği çalışmasında UFRS 16 ile UMS 17'yi karşılaştırmış buna ek olarak Almanya ve Türkiye'de hisse senetleri halka açık olan hava yolu şirketlerinin finansal durumuna etkisini incelemiştir. Çalışmada yazar yeni standardın muhasebenin şeffaflığı, önemlilik ve gerçeğe uygun sunum ilkelerini karşılamada daha etkili olacağı sonucuna ulaşmıştır. Ayrıca yeni standardın etkisinin sektörel olarak değişiklik göstereceği ve faaliyet kiralamasına ağırlık veren işletmelerin daha çok etkileneceği sonucuna ulaşılmıştır. Aktaş, Kargın ve Arıcı 2017 yılında gerçekleştirdikleri çalışmalarında TFRS 16'yı hem muhasebeleştirme açısından hem de finansal tablolara ve oranlara etkisi açısından ele almışlardır. Yeni standart çerçevesinde muhasebe uygulamalarının nasıl olacağının açıklandığı çalışmada kiralama 
tutarlarının yoğun olduğu iki halka açık işletmenin finansal tabloları da incelenmiştir. Bulunan sonuçlara göre işletmelerin borçlanma oranlarında olmakta ve farklı sektörlerdeki şirketler farklı şekilde değişikliklerden etkilenmektedir.

\section{YÖNTEM}

Çalışmanın bu bölümünde TMS 17'den TFRS 16'ya geçişin işletmelerin finansal tabloları ve finansal oranları üzerindeki olası etkileri incelenecektir. Bu çerçevede Ekim 2018 itibariyle Borsa İstanbul (BiST)'da ilk 100 endeksinde yer alan şirketlerin finansal verileri incelenmiştir. BIST 100 endeksinde bulunan şirketlerden mali kuruluşlar çalışmanın kapsamı dışında bırakılmış ve geriye kalan 63 şirketin 2017 yılına ait finansal tabloları ve dipnotları incelenmiştir.

TFRS 16'nin, örneklemi oluşturan şirketlere etkisinin ölçülmesinde Imhoff, Lipe ve Wright tarafından 1991 yılında geliştirilen “Kiralamaları Aktifleştirme Yöntemi (Lease Capitalization Method)” kullanılmıştır. Bu yöntem akademik çalışmalarda sıklıkla kullanılan (Beattie, vd. (1998), (Bennet ve Brandbury (2003), Duke vd. (2009), Singh (2010 ve 2011), Wong ve Joshi (2015), Sarı vd. (2016)) ve kabul görmüş bir yöntemdir.

Bu yöntemin uygulanmasında ilk olarak örneklemi oluşturan şirketlerin 2017 yılı finansal tablo dipnotları incelenerek 1.1.2017 tarihindeki iptal edilemez faaliyet kiralaması tutarları ve vadeleri belirlenmiştir. Vadelerin genel olarak 1 yıldan az, 1-5 yıl arası ve 5 yıldan fazla olarak sınıflandırıldığı tespit edilmiştir. Faaliyet kiralamasına ilişkin finansal veriler kullanılarak şirketlerin TFRS 16 standardını 2017 yılında kullanmaları halinde varlıklarda ve yükümlülüklerde raporlanması gereken kullanım hakkı varlık ve kiralama borçları tutarları hesaplanacaktır. Buna ek olarak finansal tablo dipnotlarından örneklemi oluşturan işletmelerin 2017 yılında gelir tablosunda raporladıkları kira giderleri tespit edilmiştir. Kira giderlerinin tespit edilmesinin nedeni, TFRS 16 standardı kullanılması durumunda bu kira giderlerinin olmayacağı ve bu durumun gelir tablosunu etkileyeceği varsayımıdır.

TFRS 16'nın etkisinin ölçümünde varlık ve yükümlülük olarak finansal durum tablosunda raporlanacak tutarların, gelir tablosunda aktifleştirilen kiralama işlemlerinden kaynaklanan yılık amortisman gideri ve faiz gideri tutarlarının hesaplanması gerekmektedir. Bu hesaplamaların yapılabilmesi için bazı varsayımların kullanılmalıdır. Kullanılan varsayımlar aşağıdaki gibidir:

Yükümlülüklerde kısa dönem ve uzun dönem ayrımı yapılmamıştır. İskonto oranı olarak 10 yıl vadeli devlet tahvillerinin faiz oranı kullanılmıştır. İskonto oranı \% 11,31'dir. Faaliyet kiralamalarının 2017 yılı gelir tablosuna etkisinin ölçülebilmesi için faaliyet kiralamalarının 1.1.2017 tarihindeki bugünkü değerleri hesaplanmıştır. Faaliyet kiralamalarından kaynaklanan ödemelerin yılsonunda olduğu kabul edilmiştir. Bu durumda faaliyet kiralamasına ilişkin kiralama borçlarının faizinin de 31.12.2017 tarihinde ödendiği kabul edilmiştir. Şirketler faaliyet kiralamasına ilişkin vade bilgilerini 1 yıldan az, 1-5 yıl arası ve 5 yıldan fazla olarak sunmaktadır. İskonto oranı olarak 10 yıl vadeli devlet tahvilleri dikkate alındığı için 5 yıldan uzun kiralamaların da en fazla 10 yıla kadar süreceği kabul edilmiştir. 1-5 yıl ve 5-10 yıl arası olan kiralamalarda her yıl eşit kira ödemesi olacağı kabul edilmiştir. Bu durumda 1-5 yıl arası toplam olarak raporlanan kira ödemesi tutarı 4'e, 510 yıl arası toplam olarak raporlanan kira ödemesi tutarı ise 5'e bölünerek yıllık ödenmesi gereken faaliyet kiralaması tutarları hesaplanmıştır. Amortisman hesaplamasında kullanım hakkı varlığın faydalı ömrü gerekmektedir. İskonto süresi ve en uzun kiralama vadesi 10 yıl kabul edildiği için faydalı ömür de 10 yıl kabul edilmiştir. Amortisman yöntemi olarak eşit paylı (doğrusal) amortisman yöntemi kullanılmıştır. Kiralama süresi sonunda kullanım hakkı varlığın ve kiralama borçlarının defter değerlerinin sıfır olacağı kabul edilmiştir. TFRS 16 standardına göre hesaplamalar yapılırken 2017 yılına ait faaliyet kiralaması giderleri gelir tablosunda dikkate alınmamıştır.

\section{BULGULAR}

İlk olarak örneklemi oluşturan 16 şirketin finansal tablo kalemleri ve faaliyet kiralaması verileri tek bir şirket gibi dikkate alınmıştır. Şirketlerin finansal tablo dipnotlarından elde edilen ve 1 yıldan az vadeli iptal edilemez faaliyet kiralaması tutarı 6.387.646.897 TL, 1-5 yıl arası olanlar 19.440.817.271 TL ve 5 yıldan uzun vadeli olanlar 17.892.219.976 TL'dir.

Varsayımlarda da belirtildiği gibi 1. yılın kira tutarı 2017 yılı sonunda ödenecektir. 1-5 yıl arası olan toplam tutar 4'e bölünmüş ve 2.,3.,4. ve 5. yıllarda ödenmesi gereken kira tutarı belirlenmiştir. 5 yıldan fazla olan kiralamalarda toplam tutar 5'e bölünerek gelecek 5-10 yıl arası ödenmesi gereken kira tutarı hesaplanmıştır.

Bir sonraki adımda iskonto oranı kullanılarak gelecek 10 yıla ait kira ödemelerinin bugünkü değerleri, henüz gerçekleşmemiş faiz gideri ve her yıl ödenecek anapara ile faiz tutarları hesaplanmıştır. Anapara ödemeleri toplam tutarı 26.875.912.306 TL olarak hesaplanmıştır. Bu tutar gelecekteki faaliyet kiralaması ödemelerinin bilançoda varlık ve yükümlülük olarak raporlanması gereken bugünkü değeridir. Örneklemi oluşturan şirketler için tek bir finansal durum tablosu oluşturulması halinde bu tabloda kullanım hakkı varlık ve kiralama borçları 26.875.912.306 TL olarak raporlanacaktır.

Finansal durum tablosunda raporlanan kullanım hakkı varlık için 2017 yılında amortisman gideri raporlanması gerekmektedir. Daha önce belirtildiği gibi faydalı ömür 10 yıl, amortisman yöntemi ise eşit paylı amortisman yöntemi olarak belirlenmiştir. Bu durumda 2017 yılına ait amortisman gideri aşağıdaki gibi hesaplanacaktır.

2017 yılı amortisman gideri $=26.875 .912 .306 \mathrm{TL} / 10 \mathrm{yll}=2.687 .591 .231 \mathrm{TL}$

Faaliyet kiralamasına ilişkin borçların yükümlülüklerde raporlanması durumunda bu borca ilişkin faiz gideri raporlanması gerekir. 2017 yılına ait faiz gideri 1.1.2017 tarihindeki anapara borcu ile faiz oranının çarpılması ile hesaplanır. Tabloda 3.039.665.682 TL olarak sunulan tutarın hesaplanması aşağıdaki gibidir.

2017 yılı faiz gideri $=26.875 .912 .306 \mathrm{TL}$ x $\%$ 11,31 = 3.039.665.682 TL

Faaliyet kiralamalarını aktifleştirmenin 31.12.2017 tarihli finansal durum tablosu ve 2017 yılı gelir tablosuna etkisi aşağıda sunulmuştur. 
Çalışmada Yer Alan Şirketlerin 31.12.2017 Tarihli Finansal Durum Tablosu (TL)

Varlıklar

\begin{tabular}{ll|l}
\hline Kullanım Hakkı Varlık & 26.875 .912 .306 & Kiralama Borçları \\
Birikmiş Amortismanlar & $(2.687 .591 .231)$ &
\end{tabular}

\begin{tabular}{|l|}
\hline \multicolumn{2}{|c|}{$\begin{array}{c}\text { Çalışmada Yer Alan Şirketlerin } \\
2017 \text { Yılı Gelir Tablosu (TL) }\end{array}$} \\
\hline$\frac{\text { Faaliyet Giderleri }}{\text { Amortisman Gideri }}$ \\
$\frac{\text { Finansman Giderleri }}{\text { Faiz Gideri }}$
\end{tabular}

Finansal durum tabloları incelendiğinde görüldüğü gibi TFRS 16'nın 2017 yılında uygulanıyor olması halinde TMS 17'ye göre şirketlerin 1.1.2017 tarihinde toplam olarak yaklaşık 26,88 milyar TL daha fazla varlık ve yükümlülük raporlamaları gerekmektedir. Ayrıca yukarıda yer alan gelir tablosunda şirketlerin TMS 17 kapsamında raporlayamayacağı yaklaşık 2,69 milyar TL amortisman gideri ve 3,03 milyar TL faiz gideri raporlanmaktadır. Gelir tablosunda raporlanan tutarlar 2017 yılında TFRS 16 uygulanıyor olsaydı çalışmada yer alan şirketlerin amortisman giderleri ve faiz giderlerindeki artışı ifade etmektedir. Varsayımlarda belirtildiği üzere; 2017 yılına ait 5.316.396.591 TL tutarındaki faaliyet kiralaması gideri 0 TL olarak kabul edilmiştir.

Çalışmanın devamında 16 şirketin başlıca finansal tablo kalemlerinin TMS 17 ve TFRS 16 uygulanması durumunda tutarları ve değişimleri aşağıdaki tabloda sunulmuştur.

Tablo 1: TMS 17 ve TFRS 16’ya Göre Başlıca Finansal Tablo Kalemlerinin Tutarları ve Değişimleri

\begin{tabular}{|l|c|c|c|c|c|c|}
\hline & $\begin{array}{c}\text { Dönem Kârı } \\
(\mathrm{TL})\end{array}$ & $\begin{array}{c}\text { Finansman } \\
\text { Gideri Öncesi } \\
\text { Faaliyet Kârı } \\
(\mathrm{TL})\end{array}$ & $\begin{array}{c}\text { Esas Faaliyet Kârı } \\
(\mathrm{TL})\end{array}$ & $\begin{array}{c}\text { Faiz Gideri } \\
(\mathrm{TL})\end{array}$ & $\begin{array}{c}\text { Toplam Varlıklar } \\
\text { (TL) }\end{array}$ & $\begin{array}{c}\text { Toplam } \\
\text { Yükümlülükler } \\
(\mathrm{TL})\end{array}$ \\
\hline TMS 17 & 9.316 .048 .600 & 19.793 .564 .341 & 17.941 .670 .144 & 11.008 .710 .944 & 235.835 .014 .052 & 149.996 .790 .360 \\
\hline TFRS 16 & 8.987 .360 .343 & 22.422 .369 .701 & 20.570 .475 .504 & 14.048 .376 .626 & 260.023 .335 .128 & 173.524 .721 .451 \\
\hline Değişim (\%) & $(3,53)$ & 13,28 & 14,65 & 27,61 & 10,26 \\
\hline
\end{tabular}

\section{SONUÇ VE ÖNERILER}

Analizin ilk aşamasında finansal tablo dipnotlarında faaliyet kiralamaları hakkında tutar ve vade bilgisi raporlamış olan 16 şirket bir arada incelenmiştir. İncelemede şirketlerin 2017 yılında TMS 17 yerine TFRS 16 standardını kullandığı varsayılmıştır. Böylece hem TMS 17 hem TFRS 16 'ya göre ilgili finansal tablo kalemleri ve finansal oranlardaki etkiyi görmek mümkün olmuştur. Tüm örneklem ele alındığında TFRS 16 standardının dönem kârı üzerinde \%3,53 oranında azalış, finansman giderleri öncesi faaliyet kârında \% 13,28, esas faaliyet kârında \% 14,65, faiz giderlerinde $\% 27,61$, toplam varlıklarda \% 10,26, toplam yükümlülüklerde ise \% 15,69 artış yarattığı tespit edilmiştir.

Esas faaliyet kârındaki artışın nedeni TMS 17 standardına göre faaliyet kiralamasından kaynaklanan kira giderlerinin TFRS 16 standardında gelir tablosuna etkisinin olmadığının varsayılmasıdır. TFRS 16 standardında faaliyet kiralamaları varlıklarda ve yükümlülüklerde raporlandığı için dönemsel olarak kira gideri değil amortisman ve faiz gideri yaratmaktadır. TMS 17'ye göre gelir tablosunda toplam 5.316.396.591 TL kira gideri raporlanmıştır. TFRS 16 uygulandığı varsayımında ise söz konusu kira gideri gelir tablosunda yer almayacaktır. Ancak TFRS 16 'ya göre kullanım hakkı varlığın 2017 yılı amortisman gideri tutarı olan 2.687.591.231 TL'nin gelir tablosunda raporlanması gerekecektir. Bu tutarlar arasındaki fark olan 2.628.805.360 TL, esas faaliyet kârındaki artışı (\% 14,65) açıklamaktadır. Benzer bir durum finansman gideri öncesi faaliyet kârında da görülmekte ve \% 13,28'lik artış yaratmaktadır. TFRS 16'ya göre yükümlülük olarak raporlanan kiralama borçları faiz giderine neden olmaktadır. Bu durum 2017 yılında faiz giderlerinde yaklaşık 3,03 milyar TL $(\% 27,61)$ artış yaratmaktadır. Dönem net kârında meydana gelen azalıs ise TFRS 16 uygulanması durumunda gelir tablosunda yer alan amortisman gideri ve finansman giderlerindeki artışların, gelir tablosu dışında bırakılan faaliyet kiralaması giderinden daha fazla olmasından kaynaklanmaktadır. TFRS 16 kapsamında, faaliyet kiralamalarının finansal durum tablosunda raporlanması 2017 yılı sonunda toplam varlık ve toplam yükümlülüklerde yaklaşık 24 milyar TL artışa neden olmuştur. 


\section{KAYNAKÇA}

Acar, M., Temiz, H., Aktaş, R. (2017), "UMS 17 Kiralama İşlemleri Standardından UFRS 16'ya Geçişin Finansal Tablolar Üzerinde Etkisi: Borsa İstanbul Örneği", Muhasebe Bilim Dünyası Dergisi, 19(3), s.592-623.

AKTAŞ, R., KARĞIN, S., ARICI, N.D. (2017), "Yeni Kiralamalar Standardı UFRS 16'nın Getirdiği Yenilikler ve İşletmelerin Finansal Tablolarına ve Finansal Oranlarına Olası Etkilerinin Değerlendirilmesi", Journal of Business Research Turk, Vol:9, No:4, s.858-881.

ALTINTAŞ, T., TUREL, A.(2016), Seçmeler 2016, Muhasebe Enstitüsü Yayınları, İstanbul, s.131-140.

BEATTIE, V., EDWARDS, K., and GOODACRE, A., 1998, "The Impact of Constructive Operating Lease Capitalization on Key Accounting Ratios",Accounting and Business Research, vol.28, no.4, pp. 233-254.

BENNETT, B.K., and BRADBURY, M.E., 2003, "Capitalizing Non-Cancelable Operating Leases", Journal of International Finance Managementand Accounting, vol.14, no.2, pp. 101-114.

DISALVIO, J., DORATA, N.T. (2014), "Lease Accounting Change: It's Not Over Yet", Review of Business: Special Accounting Issue", Vol:35, No:1, S.16-22.

DUKE, J.C., HSIEH, S.J., and SU, Y., 2009, "Operating and Synthetic Leases: Exploiting Financial Benefits in the Post-Enron Era”, Advances in Accounting, Incorporating Advances in International Accounting, vol.25, no.1, pp. 28-39.

ERICSON, J., SKARPHAGEN, R. (2015), Capitalization of Operating Lease and Its Impacts on Financial Ratios, Master Thesis, Jörköping University Jörköping International Business School.

FULBIER, R.U., SILVA, J.L. \& PFERDEHIRT, M.H. (2008), "Impact of Lease Capitalization on Financial Ratios of Listed German Companies", Schmalenbach Business Review, Vol:60, Issue:2, s.122-144.

IMHOFF, E., LIPE, R., WRIGHT, D. (1991), “Operating Leases: Impact of Constructive Capitalization”, Accounting Horizons, Vol.5, No.1, s.5163.

LEE, B., PAIK, D.G., YOON, S.W. (2014), "The Effect of Capitalizing Operating Leases on The Immediacy to Debt Covenant Violations", Journal of Accounting and Finance, Vol:14, No:6, s.44-70.

PAIK, D.G.H., SMITH, J.A.L, LEE, B.B., YOON, S.W. (2015), "The Relation Between Accounting Information in Debt Covenants and Operating Leases", Accounting Horizons, Vol:29, No:4, s. 969-996.

SARI, E.S., ALTINTAŞ, T., TAŞ, N. (2016), "The Effect of the IFRS 16: Constructive Capitalization of Operating Leases in the Turkish Retailing Sector", Journal of Business, Economics and Finance, Vol:5, Issue:1, s.138-147.

SERÇEMELi, M., ÖZTÜRK, M. (2016), "Yeni Finansal Raporlama Standardı "IFRS 16 Kiralama İşlemleri"nin Getirdiği Değişimler Üzerine Bir Değerlendirme", Mali Çözüm, Sayı: 135, s.31-48.

SINGH, A., 2011, "A Restaurant Case Study of Lease Accounting Impacts of Proposed Changes in Lease Accounting Rules", InternationalJournal of Contemporary Hospitality Management, vol.23, no.6, pp. 820-839.

SiPAHI, B. (2004), Leasing İşlemleri ve Muhasebesi, Türkmen Kitabevi, İstanbul

TAI, B.Y. (2013), "Constructive Capitalization of Operating Leases in the Hong Kong Fast-Food Industry", International Journal of Accounting and Financial Reporting, Vol: 3, No:1, s.128-142.

TFRS 16: KIRALAMALAR

TMS 17: KIRALAMA IŞLEMLERI

WONG, K., JOSHI, M. (2015), "The Impact of Lease Capitalisation on Financial Statements and Key Ratios: Evidence From Australia", Australasian Accounting Business and Finance Journal, Vol:9, Issue:3, s.27-44. 